\title{
Results of a Worldwide Survey of Mathematicians on Journal Reform
}

Cameron Neylon (Curtin University, Perth, Australia), David M. Roberts (University of Adelaide, Australia) and Mark C. Wilson (University of Auckland, New Zealand)

\section{Introduction}

Scholarly communication is in a state of ferment. The shift over the last few decades from print to digital dissemination has set off a wide range of movements for change, from the radical to the more modest and incremental. At the centre of many of these debates is the move toward wider access to the research literature. Mathematics occupies an unusual place in these debates, being simultaneously radical in the degree of uptake of new approaches such as arXiv.org for rapid dissemination prior to peer review but also highly conservative in terms of the move to online-only journals and wide access models more generally.

Several surveys have examined the opinions of researchers generally (most recently Tenopir et al. [6] see also their literature review - Taylor \& Francis [5] and Solomon [4] and issues of access to funding (Solomon and Björk [2], Björk \& Solomon [1]) and DallmeierTiessen et al. [3] but few have focused on the views of mathematicians specifically. We sought to understand how those engaged in mathematical research viewed the importance of enhancing access to the mathematics research literature and their interest in a wider range of innovations, including changes to peer review and publication practice. We also aimed to get feedback from the mathematics community on specific issues they saw with mathematical journals.

\subsection{Methodology}

An online survey instrument was made available via Google Forms from 12 April 2016 and submissions were initially solicited through personal emails, social media and research mathematics mailing lists (including DMANET, the Australian Mathematical Society and the European Mathematical Society - note that the American Mathematical Society declined to advertise it). In order to increase the number of responses, we made a second wave of approaches to recent authors in mathematics journals, societies and mathematics departments worldwide. ${ }^{1}$

\footnotetext{
1 Authors' email addresses were extracted from issues of the following journals in the years 2014-16: Acta Appl. Math., Acta Inf., Acta Math. Sin. (Engl. Ser.), Adv. Comput. Math., BIT, Calc. Var. Partial Differential Equations, Comput. Math. Organ. Theory, Comput. Math. Model., Funct. Anal. Appl., Graphs Combin., Invent. Math., J. Algebraic Combin., J. Engrg. Math., J. Math. Sci. (N.Y.), J. Theoret. Probab., Manuscripta Math., Monatsh. Math., Numer. Math., Potential Anal., Probab. Theory Related Fields, Statist. Papers, Theoret. and Math. Phys. Mathematics departments were chosen with no particular plan from universities in China, Czechia, Israel, Japan, Sweden, Turkey, Azerbaijan, Iran and South Africa.
}

The survey cannot be taken as representing the general opinion of mathematicians because we have no information about who responded - full anonymity was promised to participants. However, we are confident that we reached a broad cross-section of the community. Of respondents, in the last three years, $33 \%$ have acted as an editor for a mathematics journal, $93 \%$ have authored a paper and $86 \%$ have acted as a referee.

The survey addressed general questions of desire for change, specific issues and the association of specific factors with journal prestige. Questions on prestige were framed in two different ways. In one set, respondents were asked how they personally associate specific factors with the prestige of journals. In the second set, they were asked how the community associate those same factors with the prestige of journals. This allows us to identify consistent differences between individual (self-reported) views and the assumptions those same individuals have about community views. All data, including a copy of the survey itself and raw and processed responses, and the code used for processing, are available at https:// figshare.com/projects/Survey_of_mathematical_publishing/16944.

\section{Results}

We closed the survey when it reached exactly 1000 responses, on 28 August $2016 .^{2}$

\subsection{Demographics}

Respondents self-reported as $\mathrm{PhD}$ student $(10.5 \%)$, postdoc $(15.5 \%)$, tenure-track $(7 \%)$, tenured $(57 \%)$ and other (emeritus, librarian, etc.) (10\%). Surveys in Europe and North America of career stages of researchers give very different results for the distribution of career stages. The respondent distribution is not inconsistent with these other surveys but we cannot show that the respondents are demographically representative. Geographical representation was dominated by Europe $(54 \%)$ and North America (25\%). Other respondents selected Oceania (11\%), Asia (6\%), South America (4\%) and Africa $(0.5 \%)$ as locations.

\subsection{Appetite for change}

On a five point scale from 1 being "the status-quo is completely acceptable" and 5 being "almost all [journals] need serious work", $78 \%$ of respondents selected 3, 4 or 5. Amongst respondents, there is a strong desire for

\footnotetext{
2 Thanks to Ben Rohrlach for additional exploratory analysis and help with $\mathrm{R}$.
} 
change. Free text answers describing the major perceived problems revealed serious concerns that suggest systemic issues: almost 200 journals from 57 publishers were mentioned by name as needing serious improvement. These ranged from journals at large commercial publishers and university presses to small Open Access journals that do not charge an Article Processing Charge (APC), over the whole spectrum of prestige. Table 1 gives a classification of the stated issues into main categories (from the 466 respondents who named a journal). Of particular concern is the number of respondents who had concerns with the quality of peer review. For example, 126 journals or publishers were named as being unsatisfactory in the time taken for refereeing or the time taken from acceptance to publication.

Table 1: Distribution of free-form comments by area where improvement is needed.

\begin{tabular}{lrr} 
Issue & $\mathrm{N}$ & $\%$ \\
\hline peer review quality & 139 & 30 \\
efficiency & 115 & 24 \\
price & 101 & 21 \\
other quality & 83 & 17 \\
access & 72 & 15 \\
ethics & 35 & 7 \\
governance & 27 & 6 \\
unclear & 15 & 3 \\
\hline
\end{tabular}

On this question, those who had acted as editors did not differ substantially from those who had not. To protect anonymity, the survey did not ask which journals editors worked for but with over 330 editors this sample must include many associated with traditionally run journals.

Figure 1 plots the suggestions for each publisher in each category by the size of the mathematics journal portfolio (or rather, by $\log _{10}$ of the number of mathematics journals to account for the two orders of magnitude range: 1-202 journals). Any publisher with at least five journals suggested is labelled. One would expect publishers with larger mathematics portfolios to garner more criticism but there is essentially little trend among publishers excluding Elsevier and Springer. Even though Elsevier publishes less than half as many mathematics journals as Springer, its journals get more suggestions for improvements in all categories but one.

\subsection{Which attributes of journals contribute to journal prestige?}

A diversity of studies continue to show that journal reputation or prestige is an important factor for authors in selecting a journal. In two sets of questions, we asked respondents how important they thought specific aspects were for journal reputation and how important they thought those same aspects were for the community's view of reputation. Results are summarised in Figure 2.

The most important factor for respondents was the quality of peer review (median rank 5). This was fol-

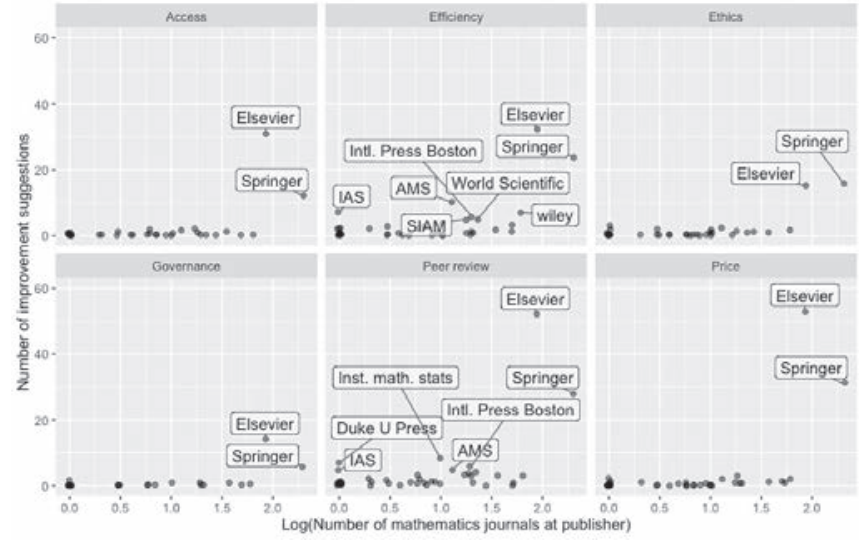

Figure 1: Number of suggestions per publisher, by category and portfolio size (small horizontal jitter added for clarity).

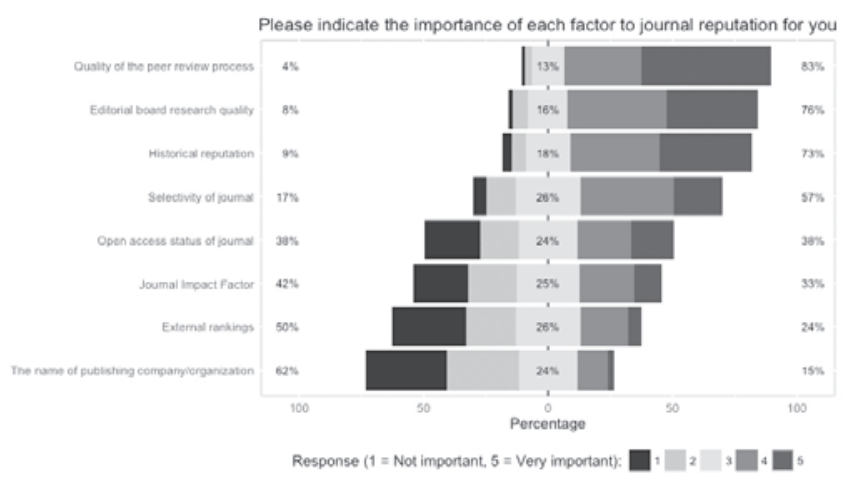

Figure 2: Stacked diverging bar chart of Likert scale responses.

lowed by the reputation of editors and historical reputation, and selectivity (median 4), then Journal Impact Factor (JIF), Open Access status and external rankings (median 3). The publisher had the lowest median ranking (2), with a mode of 1.

When we asked for the respondents' assessment of the importance of these factors in the community's view, a striking pattern emerged, as shown in Figure 3. For factors that might be considered as traditional markers of prestige (publisher, external rankings, JIF), respondents believe they matter more to the community than they do to themselves. That is, respondents tend to believe themselves less influenced by such "external" factors than the community. For other "traditional" markers (editors' reputation, historical reputation, degree of selectivity), this was less pronounced but the tendency is in the same direction.

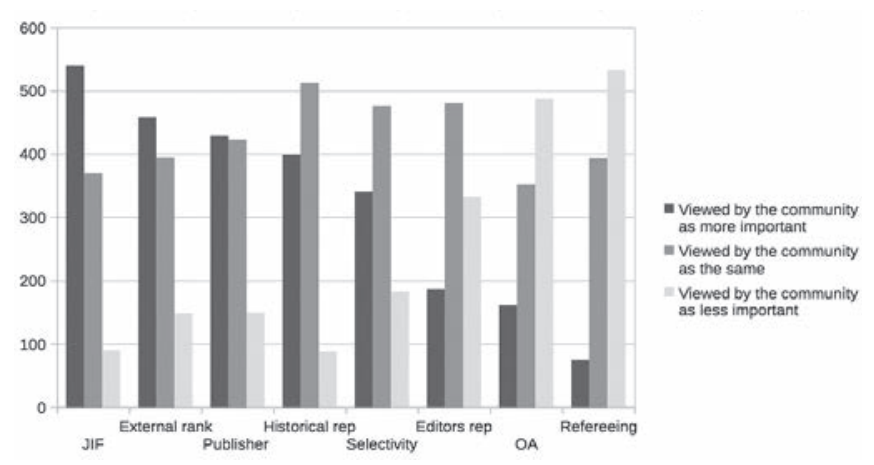

Figure 3: Respondents' beliefs about community opinion on issues. 
When asked about Open Access (OA), respondents implied strongly that it was more important to them than the community. Combined together, this shows that our respondents believe their colleagues to be more influenced by traditional markers and less interested in OA than they are. These differences matter. Change is risky. If mathematicians are pessimistic about their colleagues' desire for change then working for change is much less appealing. It is one thing for the status quo to be supported by peer pressure but it appears it may be supported by the perception of peer pressure.

Finally, the difference between personal and community views on the importance of the peer review process was both striking and disturbing. By a strong margin, most respondents view the quality of peer review as more important to themselves than they believe it is to the community. If this is true beyond our sample, it is concerning because it suggests that individuals do not see the community as a whole as driven by high standards. While this is potentially a result of sample bias, further investigation of this finding should be carried out.

\subsection{Changing practice}

If there is change, what should it look like? When asked to rate the importance of elements of journal publishing, high ethical standards and timely and thorough peer review were rated the most important (median 5). All other factors (Open Access, low cost of publication, nonprofit status, transparent costings, community control and use of modern internet technologies) had a median ranking of 4 . The most frequent ranking (mode) was 5 for all of these questions, apart from low cost. Perhaps more informatively, there is greater distribution in responses for those lower ranked priorities. In terms of the specifics of change, editors are less keen on Open Access than non-editors. This may be related to their having a substantially stronger view that author payments for publication are unacceptable (see Section 2.5).

In terms of new practices, almost a quarter of respondents supported open peer review as a default (with opt-out) and half supported post publication review with moderated comments and commenter identities revealed. Nearly half supported the publication of anonymous referee reports, suitably presented, to help readers. Free-form responses were also allowed and, of the 53 constructive suggestions made, 11 mentioned double-blind refereeing. Editors were clearly less favourable towards open review ( $26 \%$ vs. $38 \%$ ) and community election of editors ( $31 \%$ vs. $43 \%$ ) than non-editors. Interestingly, editors were slightly more supportive of banning monetary payments to editors ( $45 \%$ vs. $41 \%$ ) and of editor term limits ( $31 \%$ vs. $29 \%)$.

\subsection{Funding of increased access}

Because mathematics is a discipline with relatively little funding and therefore has limited discretionary resources, it is commonly believed that there is a strong aversion to author publication charges (APCs). However, opinions on APCs were split, with (roughly) a quarter believing them unacceptable in principle, a quarter saying they

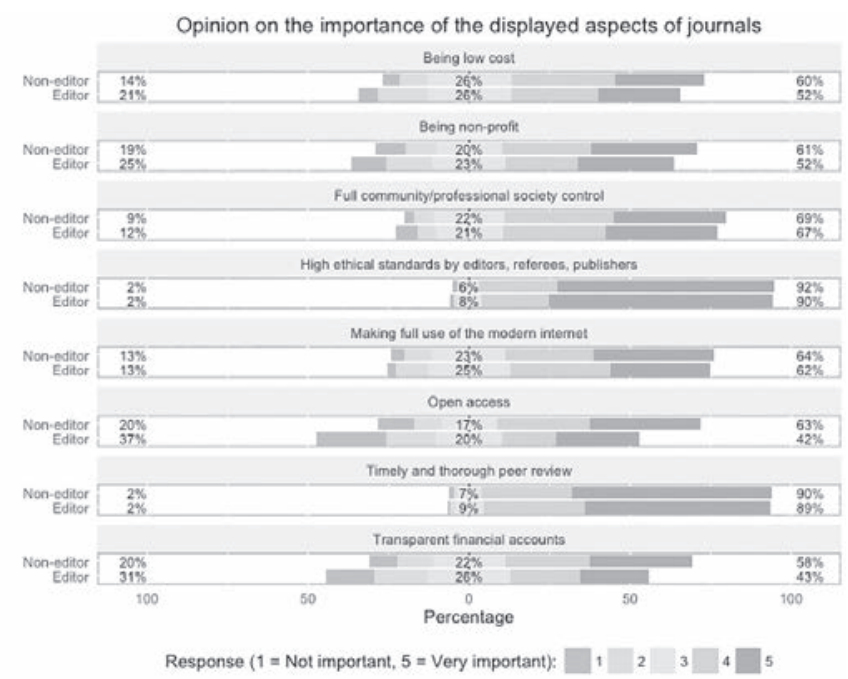

Figure 4: Importance of journal aspects: editors and non-editors.

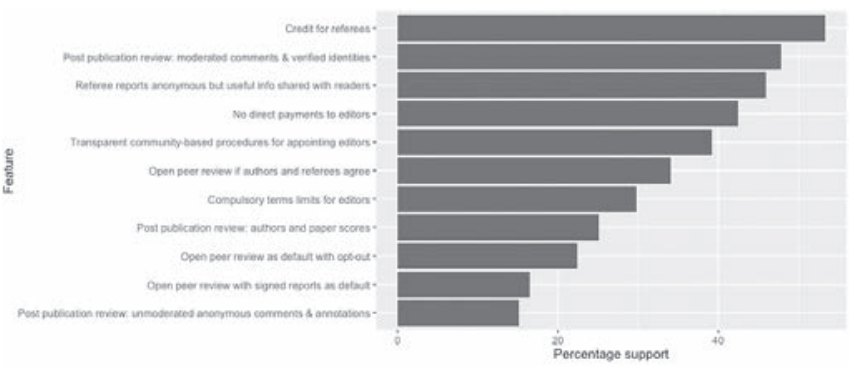

Figure 5: Support for new practices.

should be paid by library consortia and a quarter saying they were "OK if they are sufficiently low". Respondents were, however, united on one issue. Only $2 \%$ believed that they were "not a problem, and competition in the journal market will take care of them".

\section{Discussion}

Overall, we interpret these results as showing that respondents are strongly in favour of change in the publishing system but pessimistic about the support the efforts for such change would get from their colleagues. There is strong support for high(er) ethical standards and high quality peer review, and substantial support for rather radical changes to the way journals operate. These issues are also the subject of serious concerns raised in free-text answers. Editors and publishers should take note of these concerns, alongside the demand for greater transparency in editor selection and editorial processes. On several of these issues, editors' views diverge from that of the community and this should be a subject of some concern. However, there is substantial agreement between editors and non-editors on many issues.

When asked what should happen if efforts by editors to reform a journal are blocked by the publisher, over half of respondents favoured resigning to join a better journal $(29 \%)$ or to create a new one $(32 \%)$. Only a very small proportion (4.5\%) favoured settling for the status quo. For this set of respondents at least, the appetite for change is there and community support 
for bold moves by editors on behalf of the community is strong.

To our knowledge, no previous study has sought to compare the views of individuals with their views of the community. Although it may reflect a sampling bias, it is striking that respondents to this survey show a strong tendency to claim views that are more aligned with change than those they believe the community hold, particularly on Open Access and traditional measures of prestige and quality. This is in sharp contrast to their views on peer review, where there appears to be pronounced scepticism on the importance other members of the community place on the quality of peer review.

\subsection{How is Europe different?}

We recalculated some of the results for the subset of data in which the respondent indicated they work in Europe. One difference observed is that European respondents were somewhat keener on Open Access than nonEuropeans (the distribution of European answers stochastically dominated the non-European). In terms of demographics, there were more $\mathrm{PhD}$ students and fewer editors in the European respondent set than the nonEuropean but the differences were not very large. However, we have not delved into this issue rigorously and leave it to our European colleagues to analyse our publicly available data.

\section{References}

[1] B.-C. Björk and D.J. Solomon. How research funders can finance APCs in full OA and hybrid journals. Journal of the American Society for Information Science and Technology, 27:93-103, 2014.

[2] Bo-Christer Björk and David Solomon. Developing an effective market for open access article processing charges. URL: https:// wellcome.ac.uk/sites/default/files/developing-effectivemarket-foropen-access-article-processing-charges-mar14.pdf (as of: 9 November 2016), 2014.
[3] S. Dallmeier-Tiessen, B. Goerner, R. Darby, J. Hyppoelae, P. IgoKemenes, D. Kahn, and S. Lambert. Open access publishing - models and attributes. 27:93-103, 2010.

[4] D.J. Solomon. A survey of authors publishing in four megajournals. PeerJ, 2:e365, 2014.

[5] Taylor \& Francis. Open Access Survey: Exploring the view of Taylor and Francis and Routledge authors. http://www.tandf.co.uk/ journals/explore/Open-Access-Survey-March2013.pdf.

[6] Carol Tenopir, Elizabeth Dalton, Lisa Christian, Misty K. Jones, Mark McCabe, MacKenzie Smith, and Allison Fish. Imagining a gold open access future: Attitudes, behaviors, and funding scenarios among authors of academic scholarship college and research libraries. College \& Research Libraries, September 2017. http:// www.infodocket.com/2016/10/06/research-article-imagining-agold-open-access-future-attitudes-behaviors-and-funding-scenarios-among-authors-of-academic-scholarship-preprint/.

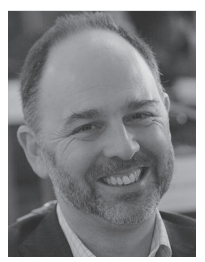

Cameron Neylon [Cameron.Neylon@curtin.edu.aul is a professor of research communications at Curtin University.

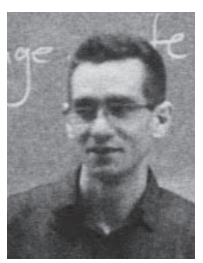

David M.Roberts [david.roberts@adelaide. edu.au] is a visiting mathematician at the University of Adelaide.

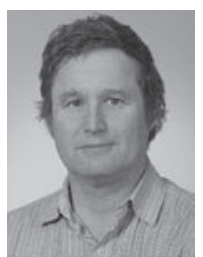

Mark C.Wilson [mcw@cs.auckland.ac.nz] is a senior lecturer at the Department of Computer Science, University of Auckland. 